\title{
Online Communication and Luxury Heritage Brand towards the E-HBC Matrix
}

\author{
Vittoria Marino $^{1} \&$ Raffaella Montera ${ }^{1}$ \\ ${ }^{1}$ Department of Business Science, Management \& Innovation Systems (DISA-MIS), University of Salerno, Italy \\ Correspondence: Raffaella Montera, Department of Business Science, Management \& Innovation Systems \\ (DISA-MIS), University of Salerno, Via Giovanni Paolo II, 132, 84084 Fisciano (SA), Italy. E-mail: \\ rmontera@unisa.it
}

Received: December 19, 2018

Accepted: January 20, 2019

Online Published: February 19, 2019

doi:10.5539/ijbm.v14n3p15

URL: https://doi.org/10.5539/ijbm.v14n3p15

\begin{abstract}
Communicating the luxury heritage brand is a new frontier of online communication. This paper intends to evaluate the online communication of the heritage brand in terms of identity traits and management aspects of a corporate group operating in luxury goods, to help fill some gaps in the literature. Using a case study on the LVMH Group, one of the most iconic luxury conglomerates, we selected 35 historic brands, in order to highlight those ambits of heritage that function well and those areas that require improvements on a communication level. Our objective is to identify the types of online communication and relative possibilities of development using the new model of the e-Heritage Brand Communication Matrix. The data is collected by a team of web marketing experts for luxury goods. The results are discussed from an intra- and inter-sectorial perspective.
\end{abstract}

Keywords: heritage brand, heritage brand identity, heritage brand management, luxury group, case study

\section{Introduction}

Luxury is living a new era characterized by a slowdown in the growth (Bain \& Company, 2016). This sector, which has always been believed crisis-proof, is now suffering the consequences of an unstable geopolitical situation and is reaching the stage of maturity in its life cycle and therefore needs a rethinking of strategy for luxury brands, induced mainly by the use of new technologies used to reach and engage consumers.

In this scenario, a valid reaction of the brand would be to enhance online communication and explore the new frontiers of a novel and clever combination of luxury and heritage. The decision to participate in the digital environment is crucial for luxury brands (Hennings, Wiedmann, \& Klarmann, 2012) above all in presence of a heritage. It is due to at least two reasons.

Firstly, brand heritage is particularly pertinent for product and service brands having a premium or luxury value position (Fionda \& Moore, 2009). Furthermore, heritage is an asset for luxury brands (Dion \& Borraz, 2015) and a source of competitive advantage (De Wit \& Meyer, 2010), difficult to imitate. It occurs when specific marketing and communication skills allow to activate the hidden potential of heritage (Burghausen \& Balmer, 2014) in terms of greater value for consumers and other stakeholders (Wiedmann, Hennigs, Schmidt, \& Wuestefeld 2011).

Secondly, luxury heritage brands can effectively position themselves in the contemporary digital marketplace considering its advantages. The potential of the Internet can be summarized in its nature: it is a global medium, fast and affordable, characterized by availability and accessibility, regardless of time and the user's location, who is attracted by all the information available on the net (Chaffey, Ellis-Chadwick, Mayer, \& Johnston, 2008) and is therefore quite exposed to online luxury goods (Okonkwo, 2009). In particular, websites play an essential role in communication to key stakeholders because they are considered by Mangold and Faulds (2009) as important brand element and much-employed source for brand contacts in contemporary markets. Nevertheless, many luxury brands are still reluctant to build a strong presence in the digital landscape fearing to break with tradition and lose their exclusive positioning (Okonkwo, 2010). Hence the need to assess the online communication of the brand's heritage, so as to identify strengths and weaknesses in the action of exploitation of the potential of the heritage brand in the digital environment.

In addition to the current relevance of the topic, this work is also justified by the attempt to help fill a gap in the 
literature. It shows, in fact, a conceptual gap already exposed in the works of Balmer and Burghausen (2015), which call for further studies on the possible connections between constructs and frameworks so far proposed in the Heritage domain, focusing also on a cross-fertilization between the different social science disciplines. Therefore, we proceed to combine the conceptual models of Heritage Brand Identity (HBI) and Heritage Brand Management (HBM), as indicators of the heritage brand in the context of digital communication of luxury heritage brands. In this sense, this paper represents an evolution in terms of conceptualization and empirical validation of propositions already known in the scientific community. The combination of HBI and HBM also leads to the elaboration of a new modelling represented by a classification matrix, existing and predictive, for the types of online communication concerning the heritage of luxury brands. In light of the above mentioned gap, we want to consider modes of communication of brand heritage, verifying compatibility and the possibility of integration between the heritage brand for luxury goods and the digital environment. In particular, the aim of the research is to evaluate online business communications of the heritage brand for a company operating in luxury goods. In this perspective, the study circumscribes and addresses two questions: one concerning the evaluation of its identity traits, the other, the evaluation of the managerial aspects of the brand's heritage for luxury brands within a luxury group.

This paper is organized as follows. Given a brief description of the theoretical background, the case study method is illustrated. Main results are then introduced and discussion of the research aim is addressed. Finally, conclusions are drawn and the limitations and the further direction of the study are examined.

\section{Theoretical Background}

\subsection{Defining the Identity of Heritage Brands}

The heritage concept is suited to brands because heritage is a dynamic and contextual representation and brands very frequently appear and disappear (Pecot \& De Barnier, 2017). Heritage brands are long-standing brands characterized by the enduring core values and legacies that create timeless relationships with stakeholders (Balmer, Greyser \& Urde, 2004; Urde, Greyser, \& Balmer, 2007; Balmer, 2017). Heritage brands have these characteristics in all their multiple identities that are the actual, ideal, desired, and communicated identities (Balmer \& Greyser, 2002).

Heritage is a component of brand equity but it is recently considered as a distinct conceptual category (Hudson, 2013). The concept of heritage brand is first referred to the Swedish monarchy (Balmer et al., 2004) analyzed through a corporate branding lens underling that monarchy can be investigated as corporate brand and managed similarly to brand with heritage. It follows an extended concept development thanks to Urde et al. (2007). These authors state that the heritage brand is a brand dimension based on longevity, basic values, symbolism, history and the awareness on the part of the company of the importance of these factors. These elements, if all present in the brand, determine a high heritage quotient. In addition, Urde et al. (2007) point out that the brand with a heritage is a different concept from the heritage brand that is part of a brand's value proposition and identity. Thus, brand should nurture, maintain, and protect its heritage to make stronger corporate marketing. Rindell, Santos Pinto, and de Lima Pinto (2015) identify the corporate image heritage as a sixth element on which the heritage brand is based.

The marketing literature looks at the heritage brand as a growth factor of the value of the brand as perceived by consumers through the establishment of strong emotional and symbolic ties (Ballantyne, Warren, \& Nobbs, 2006). In other words, heritage adds to brand authenticity (Fionda \& Moore, 2009), sincerity and differentiation (Merchant \& Rose, 2013) reducing the purchasing risks (Steewart-Allen, 2002).

\subsection{Managing Heritage Brand}

A first reflection on the management of the heritage brand comes from Balmer, Greyser, and Urde (2006), according to whom top management should manage the brand heritage in the awareness of his-trans-temporal nature, of the need to avoid impoverishing its symbols and maintaining its important emotional bases and current values. A few years later, Balmer (2009) adds that managing a heritage brand means focalising on the preservation and symbolism of the heritage, on the formation of a significant public profile, on the anticipation of change, on the rapid response to crises, on maintaining public favour and the creation of empathy. This is possible if we refer to a modus operandi called "Chronicling corporate heritage brands" (Balmer, 2009, p. 26).

An integrated framework for the management of the heritage brand has been recently proposed by Urde and Greyser (2015). It is the Heritage Brand Identity Process (HBIP), that goes through some basic steps. An essential prerequisite for successful management is heritage brand stewardship (Urde et al., 2007). This is a managerial mindset orientated to a sense of responsibility, long-term continuity, the maintenance of confidence 
in the brand and adaptability. Santos, Burghausen, and Balmer (2016) identify three uses of the heritage for branding purposes. It works as a tactical tool, a strategic asset or a strategic reference point for the development of branding strategies.

\subsection{Pertinence to Luxury Heritage Brand Communication}

The heritage brand communication is defined as everything a company says, does and communicates in terms of heritage brand, simultaneously coordinating the atemporal aspect of the historic heritage of the brand and its importance for the future generations of stakeholders (Balmer, 2013). In these terms, the heritage brand communication transmits to its various stakeholders, who change over time, the principal identity traits and management aspects of the heritage brand for the past, present and future. Communicating heritage thus endows the brand with a differentiator in terms of positioning, which can generate a lasting competitive advantage.

The centrality of the role of communication of the heritage brand takes on full force in reference to luxury brands, i.e. those brands that boast an established brand identity, a strong reputation, the ability to summon to mind exclusivity and high quality, and high customer loyalty (Phau \& Prendergast, 2000). Luxury brands are called upon to communicate a dream, to fascinate and astound its consumers (Kapferer \& Bastien, 2009). The heritage brand helps to create that dream and avoids it fading away whenever a luxury item is sold and therefore loses its exclusivity. This is possible if the luxury brands remain faithful to their heritage brand identity, gaining authenticity, credibility and distinctiveness of its offer on the markets through a story that emotionally connects the brand to the consumers (Chevalier \& Mazzalovo, 2008). However, this does not mean managing the heritage brand as a static patrimony (Morley \& McMahon, 2011). Therefore, the creation of the dream must be accompanied by the communication of a heritage brand management that is orientated towards the innovation, redefinition, strengthening and protection of the heritage of the brand. In fact, this is necessary also for those luxury brands armed with a long history, in order to intercept the current and emerging needs of the market, without irresponsibly exploiting its heritage.

An effective channel of communication at relatively low development costs is offered by Internet, which allows the transmission of the heritage of the luxury brand to a wider audience of recipients (Okonkwo, 2010), making it possible, at the same time, to establish deeper relationships with consumers of luxury goods (Christodoulides, 2009). The sheer size of the net is also well suited to the current tendency of democratisation of luxury goods (Silverstein \& Fiske, 2004). Against this background, the biggest challenges in the digital environment concern the awareness of the two-way nature of communication and consequently an opening to new ways of thinking and the ability to re-create the experience and the atmosphere of luxury on the web (Okonkwo, 2009), which is built on research, expectation and the desire of a product, in complete contrast to the immediacy linked with the new technologies. Among the most important Internet tools for communication with the various stakeholders on a global scale, Tian (2006) mentions company websites. Their importance is linked to the possibility of keeping in constant contact with the market, increasing brand awareness, presenting new products and making sure the heritage of the brand is well known and dynamic.

\section{Method}

Recourse is made to the case study method, that is an empirical inquiry investigating a contemporary phenomenon in depth and within its real-life context (Yin, 2017). The case study is carried out through a linear and iterative process consisting of typical phases (Yin, 2017), described as follows.

\subsection{Plan}

The case study is preferred as research method because "how" questions are assumed and contemporary events are examined, but the researcher has little or no control of the events (Yin, 2017). In fact, research questions regard how a luxury group communicates the identity traits and managerial aspects of its brands in the digital environment. Furthermore, the attention is focused on contemporary events, that cannot be manipulated, such as the mix of heritage brand and online technologies to obtain a competitive advantage in luxury industry.

\subsection{Design}

An embedded single-case design is selected within the basic types of designs for case studies (Yin, 2017). The case study regards the LVMH Moet Hennessy-Louis Vuitton SA group (hereinafter LVMH), selected because it is believed to be representative of luxury industry, along with PPR-Gucci and Richemont-Cartier (Ijaouane \& Kapferer 2012). The units of analysis are based on two characteristics of the heritage brand: identity traits and management aspects (Tables 1 and 2). Both are broken down into a series of sub-features as defined by the literature on the subject (Balmer, Greyser, \& Urde, 2006; Urde, 2013; Urde \& Greyser, 2015). 
Table 1. Sub-features of HBI

\begin{tabular}{|c|c|}
\hline Sub-features & Description \\
\hline \multirow{2}{*}{ Brand core } & Promise \\
\hline & Core values \\
\hline \multirow{2}{*}{ Mission \& Vision } & Engagement beyond the aim of making money \\
\hline & Direction and inspiration \\
\hline Position & Intended or realized position in the market, and in the hearts and minds of key customers and non-customer stakeholders \\
\hline Competences & Knowledge and skills that make them different from/better than the competition \\
\hline Value proposition & Key offerings and ways of appealing to customers and non-customer stakeholders \\
\hline Personality & Combination of human characteristics or qualities that form the corporate character \\
\hline Expression & Unique or special ways of communication and expression making recognition possible from a distance \\
\hline Culture & Attitudes, ways of working and behavior \\
\hline Relationships & Nature of relationships with key customers and non-customer stakeholders \\
\hline
\end{tabular}

Source: Adapted from Urde, 2013; Urde and Greyser, 2015.

Table 2. Sub-features of HBM

\begin{tabular}{ll}
\hline Sub-features & Description \\
\hline Timelessness & Mindfulness of the past, present, and future \\
Responsibility \& Protection & Mindfulness of not depleting the corporate heritage brand and its sources \\
Saliency \& Covenant & Mindfulness of the need to maintain the relevance of the corporate brand's emotional bases \\
Adaptability \& Renewal & Mindfulness that corporate brand values speak to the present \\
\hline
\end{tabular}

Source: Adapted from Balmer et al., 2006.

\subsection{Prepare}

A protocol for the investigation is developed as a guide in conducting case study. The development of protocol is particularly useful to increase the reliability of case study research because it ensures uniformity of method by multiple researchers (Yin, 2017). We applied a procedure for the selection of 35 heritage brands (Table 3) from the brand portfolio of LVMH group which comprises 70 owned brands, variously divided into five business-related sectors.

Table 3. Thirty-five cases selected according to the longevity criterion

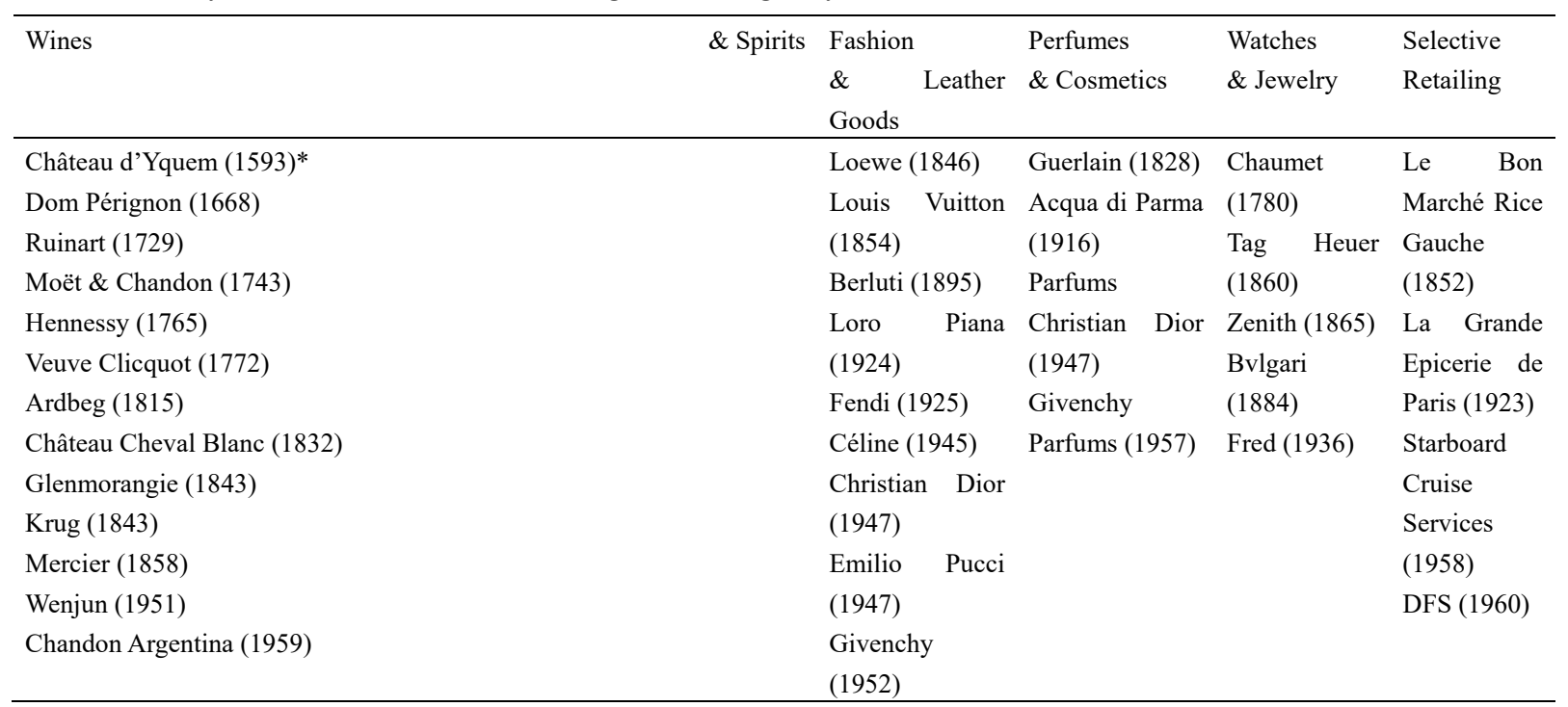

* Creation date.

Despite the difficulty of precisely determining longevity in this area, "we have found it is possible for a company to qualify as a heritage brand within a generation or two" (Urde et al., 2007, p. 8). That said, we chose to 
consider only those heritage brands at least 50 years old. Furthermore, the protocol also describes the actual research instruments used to collect and analyze the data, as follows.

\subsection{Collect}

The data collection took place in the month of September 2017, using two sources of evidence represented by documents and questionnaires in order to limit the bias effects of interpretation of a single data source.

Documents collected are public records as the official, ongoing records of an organization's activities, i.e. mission statements, annual reports or strategic plans (O'Leary, 2014). In particular, we collect the 2016 reports uploaded from January to September 2017 in section 'Investors' of the LVHM website (www.lvhm.com), because they are an official and easily accessible source of group information.

With regards to the questionnaires, the quality of responses is guaranteed by a group of experts able to offer informed opinion on web marketing for luxury goods. Professional associations, researchers' personal networks, and scientific literature are used to recruit experts. Selection criteria are specified in: a) basic biographical information (i.e. high education level); b) at least 5 publications or presentations on web marketing for luxury goods in the last year; c) at least 5 years of related experience or tenure in a position that is relevant to the issues under investigation. According to these criteria, we select 10 experts from different backgrounds including 5 academics and 5 consultants who accepted our recruitment letter. They were asked to complete a questionnaire divided into as many sections as there are sectors of the luxury field in which LVMH operates. Each section contains questions on each feature and sub-features (Tables 4 and 5).

Table 4. Questions on HBI

\begin{tabular}{|c|c|}
\hline HBI & Questions \\
\hline Identity traits & $\begin{array}{l}\text { What grade do you give to the website www.lvhm.com regarding the identity communication of heritage brands } \\
\text { owned by the group? }\end{array}$ \\
\hline Brand core & $\begin{array}{l}\text { What is the importance degree attributed by LVHM website to the communication of promise and core values } \\
\text { summing up what heritage brands stand for? }\end{array}$ \\
\hline Mission & $\begin{array}{l}\text { What is the importance degree attributed by LVHM website to the communication of aims that heritage brands } \\
\text { are engaged to achieve beyond making money? }\end{array}$ \\
\hline \& Vision & $\begin{array}{l}\text { What is the importance degree attributed by LVHM website to the communication of direction and inspiration of } \\
\text { heritage brands owned by the group? }\end{array}$ \\
\hline Position & $\begin{array}{l}\text { What is the importance degree attributed by LVHM website to the communication of the intended or realized } \\
\text { position of heritage brands in the market, hearts and minds of key stakeholders? }\end{array}$ \\
\hline Competences & $\begin{array}{l}\text { What is the importance degree attributed by LVHM website to the communication of the knowledge and skills } \\
\text { that make heritage brands different from/better than the competition? }\end{array}$ \\
\hline Value proposition & $\begin{array}{l}\text { What is the importance degree attributed by LVHM website to the communication of the heritage brands' key } \\
\text { offerings and their ways of appealing to stakeholders? }\end{array}$ \\
\hline Personality & $\begin{array}{l}\text { What is the importance degree attributed by LVHM website to the communication of the human characteristics } \\
\text { or qualities that form the heritage brands' character? }\end{array}$ \\
\hline Expression & $\begin{array}{l}\text { What is the importance degree attributed by LVHM website to the communication of unique or special } \\
\text { expressions making heritage brands recognizable from a distance? }\end{array}$ \\
\hline Culture & $\begin{array}{l}\text { What is the importance degree attributed by LVHM website to the communication of attitudes, ways of working } \\
\text { and behavior of heritage brands owned by the group? }\end{array}$ \\
\hline Relationships & $\begin{array}{l}\text { What is the importance degree attributed by LVHM website to the communication of relationships between with } \\
\text { key stakeholders and heritage brands owned by the group? }\end{array}$ \\
\hline
\end{tabular}

Source: Own elaboration.

The experts are invited via email to give a rating based on a measurement scale from a widely experimented model for assessing the quality of a website (Polillo, 2013). Polillo (2012b) states that websites need of specific approaches to quality and quality assessment because they acknowledge a major importance to information architecture and contents differently from other software applications. Within the classification of web site quality models, Polillo's works (2012a) are included in the categories of original quality models that do not derive from international standards but from experience and surveys with users that, being the ultimate target of a web site, perceive its quality (Fogli \& Guida, 2015).

To assess the quality of a website, the model of Polillo (2013) is based on identification of key features and 
sub-features of website. Thus key features are evaluated on a rating from 1 (very bad) to 5 (very good); instead, the sub-features are weighted on a scale from 0 (irrelevant) to 1 (maximum importance). In our paper, the same measurement scale is used. For each feature, therefore, experts are asked to assign a rating from 1 (very bad) to 5 (very good); for each sub-feature, experts are asked to assign a weight on a scale from 0 (irrelevant) to 1 (maximum importance). Experts provide ratings on all 35 heritage brands selected from LVMH's brand portfolio. Thanks to their intuition and expertise, they look for HBI, HBM, and relative sub-features in the 'Houses' section of LVHM website. A case study database systematically organizes the data collected.

Table 5. Questions on HBM

\begin{tabular}{|c|c|}
\hline HBM & Questions \\
\hline Managerial aspects & $\begin{array}{l}\text { What grade do you give to the website } w w w . l v h m . c o m \text { regarding the management of heritage brands owned by } \\
\text { the group? }\end{array}$ \\
\hline Timelessness & $\begin{array}{l}\text { What is the importance degree attributed by LVHM website to the communication of mindfulness of the past, } \\
\text { present, and future that coexist in heritage brands owned by the group? }\end{array}$ \\
\hline $\begin{array}{l}\text { Responsibility } \\
\text { Protection }\end{array}$ & $\begin{array}{l}\text { What is the importance degree attributed by LVHM website to the communication of mindfulness of not } \\
\text { depleting the heritage brands and their sources? }\end{array}$ \\
\hline Saliency \& Covenant & $\begin{array}{l}\text { What is the importance degree attributed by LVHM website to the communication of mindfulness of the need to } \\
\text { maintain the relevance of the brands' emotional bases? }\end{array}$ \\
\hline $\begin{array}{l}\text { Adaptability } \\
\text { Renewal }\end{array}$ & $\begin{array}{l}\text { What is the importance degree attributed by LVHM website to the communication of mindfulness that brand } \\
\text { values speak to the present? }\end{array}$ \\
\hline
\end{tabular}

\subsection{Analyze}

The multiple sources of evidence are analyzed in order to provide a data triangulation by integrating different evidence because confluence of evidence breeds credible findings (Bowen, 2009).

Documents collected are mostly texts, thus in order to analyze and interpret data a qualitative content analysis is conducted. Content analysis is a systematic, replicable technique for compressing many words of text into fewer content categories based on explicit rules of coding (Krippendorff, 1980). To organize and make sense of textual data, an open coding approach is used. The authors code 8 reports that can be downloaded from the section 'Investors' of the LVHM website. Then individually, they proceeded with the coding procedures through a manual method. Referring to the extant literature on heritage brand, the researchers identified some concepts and categories - such as 'heritage', 'legacy', 'history', 'memory', 'tradition', 'authenticity', 'inheritance', 'past' - in order to interpret the collected data. Main purpose is to verify if the textual data could be interpreted using these concepts and categories. During this stage, the coding results of the authors were compared, and, if disagreements occurred, discussions followed to improve coherence. Comparing the secondary data with the concepts and categories previously identified, we found out a partial correspondence because the words 'heritage', 'authenticity' and 'tradition' are the most frequently utilized. In this paper, content analysis is useful for painting an overall picture on the digital communication of heritage brands owned by LVHM. In fact, reports provide background information and are therefore helpful in contextualizing the research as well as in pointing to questions that need to be asked. In this sense, content analysis contributes to a more critical and comprehensive research.

Regarding the data collected using questionnaires, they are analyzed with a central tendency defined as the statistical measure that identifies a single value as representative of an entire distribution (Gravetter \& Wallnau, 2011). Mean is the most commonly used measure of central tendency (Manikandan, 2011). Weighted mean is calculated to compile a sort of report card for the website, analyzed from the point of view of the online communication of the group's heritage brands.

Within the case study, therefore, we integrate qualitative and quantitative analysis methods. Mixed methods may be used and facilitate a holistic understanding of the phenomenon under study (Yin, 2017).

\section{Results}

Report analysis reveals a good background for the research because the heritage of brands owned by LVHM is communicated in website of the group. In fact, it is evident that LVMH has built its leading position on a unique portfolio of iconic brands, deriving group's energy from exceptional heritage and innovative mindset of brands owned. For this reason, LVHM supports their traditions of excellence and the development of its heritage brands, respecting their sources of strength and uniqueness. 
Results of questionnaires are read in a intra-sector perspective. Thus, the evaluation of online communication of the group's heritage brand varies in its identity traits and management aspects within each business sector.

\subsection{Wines and Spirits}

The comparison of the weighted votes of the HBI (4.06), and the weighted vote of the HBM (2.58), shown in Table 6, clearly shows that the identity traits of the group's heritage brand are attributed much more value than the LVMH's management aspects in their online communication. In particular, the official corporate website of the group communicates extremely well these sub-features of HBI: Brand core; Personality; Expression; Culture. On the other hand, the identity trait which needs further improvement on the communicative level is without doubt the Relationships. It did in fact receive a very bad rating (1), coupled with maximum importance (1), justified, among other things, by the strong bond of brand wines and spirits with their territory of origin. One of the strengths of the communication of HBM, however, is represented by the feature of Adaptability and Renewal. The rating for the feature of Responsibility and Protection is totally inadequate, (mark: 1), coupled with protection and custody as a priority (weight: 1) for the benefit of subsequent generations of stakeholders.

\subsection{Fashion and Leather Goods}

The feature of the HBM (weighted mark: 4.75) is evaluated slightly better than that of HBI (weighted mark: 4.53) (Tab. 6). Interestingly, all the managerial aspects are considered of maximum importance (weight: 1) and for more than half adequately valorised (mark: 5) through the group's online communication for HBM. In particular we are talking about the Timelessness, Saliency and Covenant, and Adaptability and Renewal. As regards the HBI, we note that the group optimally communicates various identity traits with the maximum weight (1), such as Brand core, Position, Competences, Expression, and Culture.

Table 6. Evaluation of LVHM's online communication of the heritage brand by feature

\begin{tabular}{|c|c|c|c|c|c|c|}
\hline \multirow[b]{2}{*}{ Business Sectors } & \multicolumn{2}{|l|}{ HBI } & \multicolumn{3}{|c|}{ HBM } & \multirow[b]{2}{*}{$\begin{array}{l}\text { Weighted } \\
\text { mark }\end{array}$} \\
\hline & Mark & Weight & $\begin{array}{l}\text { Weighted } \\
\text { mark }\end{array}$ & Mark & Weight & \\
\hline Wines \& Spirits & 4 & 7.75 & 4.06 & 2.25 & 3 & 2.58 \\
\hline Fashion \& Leather Goods & 4.33 & 7.5 & 4.53 & 4.75 & 4 & 4.75 \\
\hline Perfumes \& Cosmetics & 2.22 & 6 & 2.70 & 2 & 3.25 & 2.23 \\
\hline Watches \& Jewelry & 3.22 & 6 & 3.45 & 4.25 & 3.75 & 4.33 \\
\hline Selective retailing & 3.55 & 7.25 & 3.58 & 2.75 & 2.75 & 3.18 \\
\hline
\end{tabular}

\subsection{Perfumes and Cosmetics}

The evaluation of LVMH's online communication for the heritage brand does not differ significantly between the features, so much so that Table $\mathbf{6}$ shows only a slight difference between the relative weight marks (HBI: 2.70; HBM: 2.23). The official website of the group optimally communicates only the Brand core, together with an appropriate description of the Personality. For the rest, limiting ourselves to only the sub-features to which almost maximum importance is attached (0.75), the Mission and Vision require substantial improvements for communication. The managerial mindfulness of the past, present and future is clearly shown as regards the characteristics of the HBM. The weakest aspect of communication, however, concerns the Saliency and Covenant, which is credited with a maximum weight in view of the importance of creating a timeless sensorial experience for the brand in its sector.

\subsection{Watches and Jewellery}

The management aspects of LVMH's heritage brand are evaluated better than the identity traits on the group's website. Table 6, in fact, shows HBM with a weighed mark of 4.33 versus a HBI with a weighted mark of 3.45. Not surprisingly, more than half of the sub-features of the management aspects are assigned marks that are excellent or good, which correspond to the maximum weights (1). We refer to the Timelessness, Responsibility and Protection, and Saliency and Covenant. In terms of HBI, however, we have optimal communication of the Competences and Expression. To note is the boosted enhancement of the Value Proposition and Mission and Vision in respect to the average importance (weight: 0.5 ) given to these sub-features in the watch and jewellery industry. Given their importance in this sector (weight: 1) the communication of the Personality and Culture require further improvement (mark: 2). 


\subsection{Selective retailing}

In the selective distribution, there is no significant gap between the weighted marks attributed to the features (HBI: 3.58; HBM: 3.18) (Table 6). In particular, the group optimally communicates two identity traits of maximum importance (mark: 5; weight: 1), that is, the Relationships and the Position. Certainly improved, however, is the communication of HBI in terms of Mission and Vision, and Brand core. The strongest sub-feature communicated for the HBM is the Saliency and Covenant. This contrasts with the Adaptability and Renewal, which definitely needs to be improved (weight: 1).

\section{Discussion}

An inter-sectorial reading of the research results shows a variation in the assessment of the group's online communication of the heritage brand in different business sectors. This reveals the LVMH's commitment to respect the specificity and autonomy of each brand that it owns. The best communication of the group's corporate brand heritage regards the brands from the Fashion and Leather Goods (HBI: weighted mark 4.53; HBM: weighted mark 4.75). This suggests that the group recognizes the great heritage with which this particular sector is endowed. In fact, heritage is one of the key components of the luxury brand in fashion (Fionda and Moore 2009), so much so that it also increases its economic value. The worst record, however, is held by the Perfumes and Cosmetics (HBI: weighted mark 2.70; HBM: weighted mark 2.23), for which there is considerable scope for improvement in the group's online communication of the heritage brand.

Within each sector, the evaluation level of identity traits and management aspects, expressed in weighted marks is tendentially similar. However, a certain imbalance in the communication of one of the two components of the group's heritage brand concerns the Wines and Spirits (HBI: weighted mark 4.06; HBM: weighted mark 2:58) and Watches and Jewellery (HBI: weighted mark 3.45; HBM: weighted mark 4.33). We: made a comparison of the scores attributed each time to the sub-features in the different business sectors. In this way several weaknesses in the communications group's heritage brand came to light, despite the fact that it is the world leader in luxury goods. First of all, LVMH does not transmit its immense wealth of HBI with the incisiveness that one would expect. Just think, in fact, that only two of the relative sub-features are optimally communicated (mark: 5) in 3 of the 5 business sectors (Fig. 1). In other words, the group aims primarily in its online communication at the Brand core and Expression in order to reveal their heritage brand to the web user. In this context, the identity trait most neglected is the Relationships, which scores the highest number of deficiencies (mark: 1).

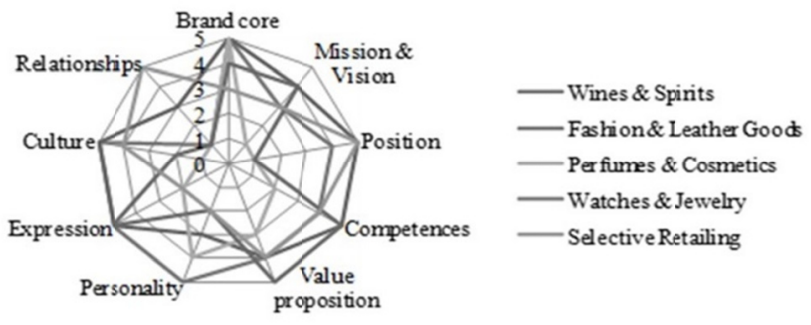

Figure 1. LVMH's HBI: score of sub-features by business sector

The need for improvement can also be found at the level of corporate brand heritage management (Fig. 2), especially in terms of Responsibility and Protection. The minimum score (mark: 1) attributed to this sub-feature in 3 sectors out of 5 shows strong inadequacy in the group's communication. In reality, this aspect constitutes a valid item to be communicated to the web user, showing them how the management assumes its role of custodian and its legitimization to act in defence of the heritage of the brand.

Nevertheless, the only well valorised sub-feature on the group's website is Timelessness, very well marked in 3 of the 5 sectors. This shows that LVMH insists on its strategic choice, consisting in a super-historical management of its brand name, capable of handing down their extraordinary heritage from generation to generation, keeping them securely in place in a modern context and providing a guarantee for the future. 


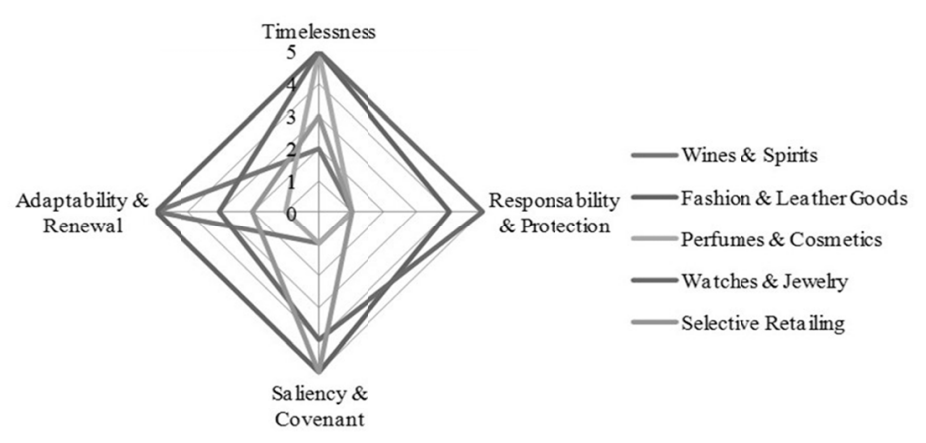

Figure 2. LVMH's HBM: score of sub-features by business sector

\section{Conclusion}

The case study allows us to achieve the research objective because it is capable of evaluating the group's online communication of heritage brand for companies operating in the luxury industry, both in terms of identity traits and management aspects.

\subsection{The e-Heritage Brand Communication (e-HBC) Matrix}

The summary of our study brings us to an original elaboration of the e-HBC Matrix, built on the HBI on the horizontal axis and the HBM on the vertical axis. The marks assignable to the sub-features range between 1 and 5. The demarcation line, drawn on each of the axes, is positioned for both the dimensions on the value of 3 , so that the dimensions are low up to 3 and high over 3 . In this way we obtain four quadrants which constitute a typological classification for the online communication of heritage brand of a company group (Fig. 3).

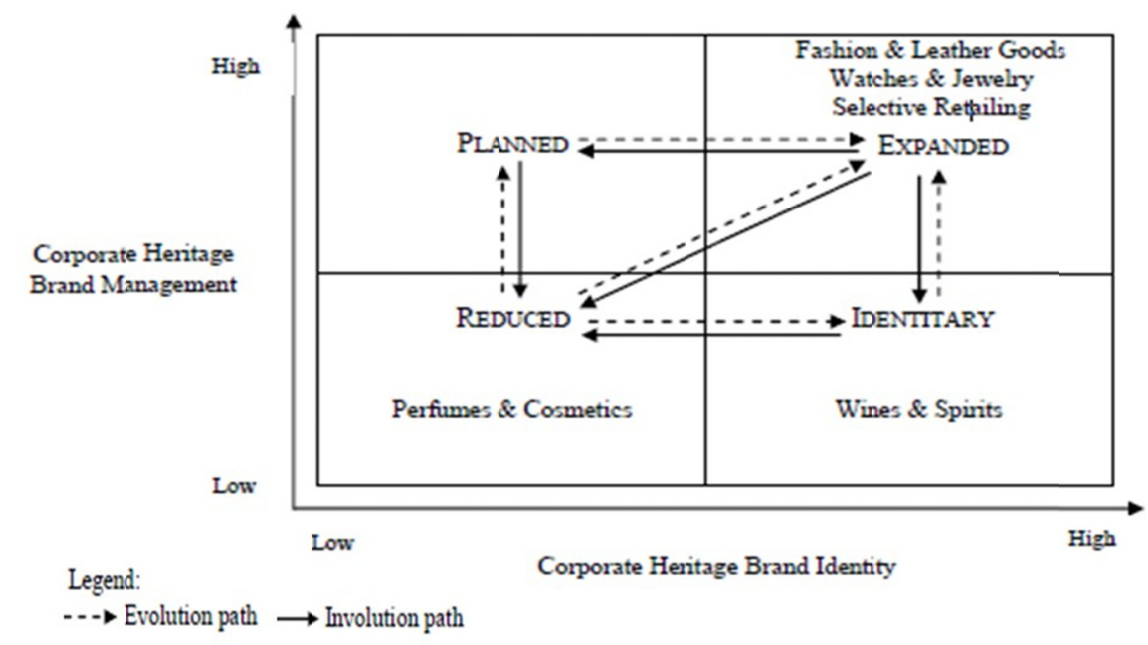

Figure 3. e-HBC Matrix: types of communication and evolutionary paths in www.lvhm.org

The specificities of each typology are directly dependent on the grades (high and low) of the identity traits and managerial aspects of the heritage of the group's brand. Finally, each business sector is placed in the matrix considering the weighted marks.

\subsubsection{The Quadrants}

The first quadrant holds the e-HBC typology called expanded. It represents the ideal to which a group should direct its communication efforts for the heritage of its brand in the digital context. It is, therefore, an online communication based on the extensive valorisation of both the identity traits and the management aspects of a group's heritage brand. The expanded typology that is found more often in LVMH's official website in regard to most of the sectors. Hence it follows that the group's heritage brand is, in general, well communicated. In terms of weighted marks, in fact, Fashion and Leather Goods (HBI: 4.53; HBM: 4.75), Jewellery and Watches (HBI: 
3.45; HBM: 4.33) and Selective Retailing (HBI: 3.58; HBM: 3.18) all lie beyond the demarcation line (of 3) on each axis. Of these sectors, however, only the Fashion and Leather Goods reaches the ideal typology of online communication of the heritage of a brand, reaching weighted marks slightly less than 5 (high).

The second quadrant includes the e-HBC typology called planned. Online communication is based on poorly emphasized identity traits of a group's heritage brand, but with a strong valorisation of the managerial aspects, resulting from planning activities. The planned typology does not deal with the online communications of LVMH's heritage of the brand in any business sector. For this reason, the second quadrant has only a theoretical significance.

The third quadrant holds the e-HBC typology called reduced. It is the type to be avoided if the communication effort is aimed at ensuring that the heritage qualities of the brand add value in terms of authenticity, credibility and distinctiveness. It is, therefore, an online communication based on a low valorisation of both the identity traits and the management aspects of a group's heritage brand. The reduced typology concerns LVMH in regard to Perfumes and Cosmetics (HBI: weighted mark 2.70; HBM: weighted mark 2.23), the only sector to be located before the demarcation line (equal to 3 ) on each of the axes.

The fourth quadrant holds the e-HBC typology called identitary. Online communication is based on extensive valorisation of identity traits, but poorly emphasizes the management aspects of the group's heritage brand. The identitary typology concerns the online communications of LVMH's heritage of brand relative to Wines and Spirits (HBI: weighted mark 4.06; HBM: weighted mark 2.58), the only sector to be located before the demarcation line (equal to 3 ) and only in correspondence with the horizontal axis.

\subsubsection{Development Paths}

The matrix also provides a vision of the eventual paths both for evolution and involution to which the four types of online communication of a group's heritage brand are subject. Both pathways include a variety of trajectories, which highlight the possible displacements of the communication typologies in one or more quadrants in various directions. For practical issues, only the trajectories that pass in a single quadrant of the matrix are considered.

A first evolutionary trajectory goes from the planned to the expanded typology, so the low HBI evolves into high, leaving unchanged the HBM. It is a path that LVMH have not taken, given the absence of the planned typology in the classification of the group's online communication. A second evolutionary trajectory goes from the reduced to the expanded typology, where both dimensions evolve from low to high. A third evolutionary trajectory goes from the reduced to the planned typology by which a low HBM evolves into high, leaving unchanged the HBI. A fourth evolutionary trajectory goes from the reduced to identitary typology by which a low HBI evolves into high, leaving unchanged the HBM. The second, third and fourth evolutionary trajectories are those taken by the Perfumes and Cosmetics of LVMH to free themselves of their terrible record held for the communication of the heritage of the brand compared to the other sectors. A fifth evolutionary trajectory, regarding the group's Wines and Spirits, goes from the identitary to the expanded typology, where a low HBM evolves into high, leaving unchanged the HBI.

As for the involution path, a first trajectory goes from the expanded to the planned typology, so a high HBI regresses into low, leaving unchanged the HBM. A second involutive trajectory goes from the expanded to the reduced typology, whereby both high dimensions regress into low. A third involutive trajectory goes from the expanded to the identitary typology, so a high HBM regresses into low, leaving unchanged the HBI. The first, second and third involutive trajectories risk being followed by a good part of the group's sectors (Fashion and Leather Goods, Watches and Jewellery, Selective Retailing). A fourth involutive trajectory goes from the planned to the reduced typology, by which a high HBM regresses into low, leaving unchanged the HBI. This trajectory is not followed by LVMH, given the absence of the planned typology in the classification of the group's online communication. A fifth involutive trajectory, regarding the Wines and Spirits sector, goes from the identitary to the reduced typology, so a high HBI regresses into low, leaving unchanged the HBM.

\subsection{Originality}

This work fits into the growing trend of studies on heritage brand. We have integrated the existing conceptual models from the literature (HBI, HBM), in order to offer new opportunities for analysis if referred to a field of research still largely unexplored as is online communications for corporations who represent the artisan world in its most noble and complete form. The study shows a modality for a quick check-up of the online communication of heritage brand inside a website. In this sense, the paper provides a set of indicators with which to start the analysis and to be concluded with a final matrix. With the help of these tools, you can identify the ambits of heritage brand that function well from the point of view of communication and the main areas 
requiring improvement measures on the communicative level, and then, on this basis, clarify the type of communication implemented online with its relative potential for development. In this way, corporate groups and single firms can understand how their communication is functioning and what could be done with the heritage brand towards strengthening or consolidating their competitive advantage. Not least, the modality we suggest is scalable, meaning that it can be used for both basic and complex portals, and can serve in comparing competing websites to identify their respective strengths and weaknesses in the heritage brand communication.

\subsection{Limitations and Future Directions}

Websites may change at any time given the fast-paced nature of the World Wide Web. For this reason, it is next to impossible to replicate this study, as it refers to data collected in September 2017. Another limitation is to be found in the subjectivity of the allocation of marks and scores from the group of experts involved in the data collection. An unbiased attitude should be a prerequisite of respondents, but this aspect is difficult to control for both experts and researchers alike. In this sense, it should be useful a less intuitive approach to find the features and sub-features that are asked of evaluation. Anyway, the effects of subjectivity are partially contained by the fact that we do not want so much to reach an objective assessment of a group's online communication of their heritage brand, but rather to find a set of indicators for strengths and weaknesses from which to plan strategies for improvement or for a complete makeover.

Furthermore, the reading of the results does not disclose the specifics of individual brands, but gives overall information on the brands of the various business sectors of the group. In future, therefore, a web content analysis could be conducted to determine the textual occurrences of the pages prepared for each brand in the official website of the group. The group's online communication for heritage brand could also be compared with the ones made by the brand on their own portals. Following research could focus not only on the study of the heritage brand communication through the website, but also extend the analysis to the entire digital marketing strategy. It would also be interesting to compare the communication of the heritage brand implemented online with one created offline, in order to determine the environment more suited to the communication the luxury heritage brand.

\section{References}

Bain \& Company (2016). Spring luxury update. Retrieved from http://www.bain.com/about/press/press-releases/spring-luxury-update-2016.aspx

Ballantyne, R., Warren, A., \& Nobbs, K. (2006). The evolution of brand choice. Journal of Brand Management, 13, 339-352. https://doi.org/10.1057/palgrave.bm.2540276

Balmer, J. M. T. (2004). The British Monarchy: Does the British Crown as a corporate brand fit? Working Paper 04/16, School of Management, Bradford University, Bradford, April.

Balmer, J. M. T. (2009). Scrutinising the British Monarchy: The corporate brand that was shaken, stirred and survived. Management Decision, 47, 639-675. https://doi.org/10.1108/00251740910959468

Balmer, J. M. T. (2011). Corporate heritage identities, corporate heritage brands and the multiple heritage identities of the British Monarchy. European Journal of Marketing, 45, 1380-1398. https://doi.org/10.1108/03090561111151817

Balmer, J. M. T. (2013). Corporate heritage, corporate heritage marketing, and total corporate heritage communications: What are they? What of Them? Corporate Communications: An International Journal, 18 , 290-326. https://doi.org/10.1108/CCIJ-05-2013-0031

Balmer, J. M. T. (Ed.) (2017). Foundations of corporate heritage. London: Routledge.

Balmer, J. M. T., \& Greyser, S. A. (2002). Managing the multiple identities of the corporation. California Management Review, 44(3), 72-86. https://doi.org/10.2307/41166133.

Balmer, J. M. T., Greyser, S. A., \& Urde, M. (2004). Monarchies as corporate brands. Harvard Business School Working Paper Series, 4-24.

Balmer, J. M. T., Greyser, S. A., \& Urde, M. (2006). The Crown as a corporate brand: Insight from Monarchies. Journal of Brand Management, 14, 137-161. https://doi.org/10.1057/palgrave.bm.2550031.

Balmer, J., \& Burghausen, M. J. (2015). Explicating corporate heritage, corporate heritage brands, and organizational heritage. Journal of Brand Management, 22, 364-384. https://doi.org/ 10.1057/bm.2015.26

Bowen, G.A. (2009). Document analysis as a qualitative research method. Qualitative Research Journal, 9, 27-40. https://doi.org/10.3316/QRJ0902027. 
Burghausen, M., \& Balmer, J. M. T. (2014). Corporate heritage identity management and the multi-modal implementation of corporate heritage identity. Journal of Business Research, 67, 2311-2323. https://doi.org/10.1016/j.jbusres.2014.06.019

Chaffey, D., Ellis-Chadwick, F., Mayer, R., \& Johnston, K. (2008). Internet Marketing: Strategy, Implementation and Practice (4th ed.). Harlow: Prentice Hall.

Chevalier, M., \& Mazzalovo, G. (2008). Luxury Brand Management: A World of Privilege. Singapore: Wiley and Sons.

Christodoulides, G. (2009). Branding in the post-Internet era. Marketing Theory, 9, 141-144. https://doi.org/10.1177/1470593108100071

De Wit, B., \& Meyer, R. (2010). Strategy: process, content, context. Amsterdam: South-Western Cengage Learning.

Dion, D., \& Borraz, S. (2015). Managing heritage brands: A study of the sacralization of heritage stores in the luxury industry. Journal of Retailing and Consumer Services, 22, 77-84. https://doi.org/10.1016/j.jretconser.2014.09.005

Fionda, A. M., \& Moore, M. C. (2009). The Anatomy of the luxury fashion brand. Journal of Brand Management, 16, 347-363. https://doi.org/10.1057/bm.2008.45

Fogli, D., \& Guida, G. (2015). A practical approach to the assessment of quality in use of corporate web sites. Journal of Systems and Software, 99, 52-65. https://doi.org/10.1016/j.jss.2014.09.006

Gravetter, F. J., \& Wallnau, L. B. (2000). Statistics for the Behavioral Sciences (5th ed.). Belmont: Wadsworth-Thomson Learning.

Hennings, N., Wiedmann, K. P., \& Klarmann, C. (2012). Luxury brands in the digital age. Exclusivity versus ubiquity. Marketing Review St. Gallen, 1, 30-35. https://doi.org/10.1002/cb.237

Hudson, B.T. (2013). Heritage brand and heritage tourism. Boston Hospitality Review, 1, 12-16.

Ijaouane, V., \& Kapferer, J. N. (2012). Developing luxury brands within luxury groups: Synergies without dilution? Marketing Review St. Gallen, 1, 24-29. https://doi.org/10.1007/s11621-012-0107-8

Kapferer, J. N., \& Bastien, V. (2009). The Luxury Strategy: Break the Rules of Marketing to Build Luxury Brands. London: Kogan Page.

Krippendorff, K. (1980). Content analysis: An introduction to its methodology (4th ed.). Newbury Park, CA: Sage.

Mangold, W. G., \&. Faulds, D. J. (2009). Social media: The new hybrid element of promotion mix. Business Horizons, 52, 357-365. https://doi.org/10.1016/j.bushor.2009.03.002

Manikandan, S. (2011). Measures of central tendency: The mean. Journal of Pharmacology and Pharmacotherapeutics, 2, 140-142. https://doi.org/10.4103/0976-500X.81920

Merchant, A., \& Rose, G. M. (2013). Effects of advertising-evoked vicarious nostalgia on heritage brand. Journal of Business Research, 66, 2619-2625. https://doi.org/10.1016/j.jbusres.2012.05.021

Morley, J., \& McMahon, K. (2011). Innovation, interaction, and inclusion: Heritage luxury brands in collusion with the consumer. Paper presented at the 13th Annual Conference for the International Foundation of Fashion Technology Institutes. Institut Français de la Mode, Paris, April.

O’Leary, Z. (2014). The essential guide to doing your research project. London: Sage Publications.

Okonkwo, U. (2009). The luxury brand strategy challenge. Journal of Brand Management, 16, $287-289$. https://doi.org/10.1057/bm.2008.53

Okonkwo, U. (2010). Luxury online. London: Palgrave MacMillan.

Pecot, F., \& De Barnier, V. (2017). Brand heritage: The past in the service of brand management. Recherche et Applications en Marketing (English Edition), 32, 72-90. https://doi.or/10.1177/2051570717699376

Phau, I., \& Prendergast, G. (2000). Consuming luxury brands: The relevance of the rarity principle. Journal of Brand Management, 8, 122-138. https://doi.org/10.1057/palgrave.bm.2540013

Polillo, R. (2012a). Quality models for web [2.0] sites: A methodological approach and a proposal. In Harth, A. \& Koch, N. (Ed.), Current trends in Web engineering. LNCS 7059. Springer, Berlin/Heidelberg, Germany, 
Polillo, R. (2012b). A core quality model for web applications. Journal of Web Engineering, 11, 181-208.

Polillo, R. (2013). Il check-up dei siti web delle organizzazioni non profit. Osservatorio ICT per il Non Profit 2013 - Il non profit in rete, Quaderni della Fondazione Think!, 3, 1-53.

Rindell, A., Santos Pinto, F., \& de Lima Pinto, A. (2015). Two sides of a coin: Connecting corporate heritage brand to consumers' corporate image heritage. Journal of Brand Management, 22, 467-484. https://doi.org/10.1057/bm.2015.20

Santos, F. P., Burghausen, M., \& Balmer, J. M. T. (2016). Heritage branding orientation: The case of Ach. Brito and the dynamics between corporate and product heritage brands. Journal of Brand Management, 23, 67-88. https://doi.org/10.1057/bm.2015.48

Silverstein, M. J., \& Fiske, N. (2004). Trading Up. La Rivoluzione del Lusso Accessibile. Milano: ETAS.

Steewart-Allen, A. L. (2002). Heritage Branding Helps in Global Markets. Marketing News, 36, 7.

Tian, Y. (2006). Communicating with local publics: A case study of Coca-Cola's Chinese web site. Corporate Communications: An International Journal, 11, 13-22. https://doi.org/10.1108/13563280610643516

Urde M. T., Greyser, S. A., \& Balmer, J. M. T. (2007). Corporate brands with a heritage. Journal of Brand Management, 15, 4-19. https://doi.org/10.1057/palgrave.bm.2550106

Urde, M. T. (2013). The corporate brand identity matrix. Journal of Brand Management, 20, $742-761$. https://doi.org/10.1057/bm.2013.12

Urde, M. T., \& Greyser, S. A. (2015). The Nobel Prize: The identity of a corporate heritage brand. Journal of Product and Brand Management, 24, 318-332. https://doi.org/10.1108/JPBM-11-2014-0749

Wiedmann, K. P., Hennigs, N., Schmidt, S., \& Wuestefeld, T. (2011). The importance of brand heritage as a key performance driver in marketing management. Journal of Brand Management, 19, 182-194. https://doi.org/10.1057/bm.2011.36

Yin, R. K. (2017). Case study research and application: Design and methods (6th ed.). Thousand Oaks, CA, USA: Sage.

\section{Copyrights}

Copyright for this article is retained by the author(s), with first publication rights granted to the journal.

This is an open-access article distributed under the terms and conditions of the Creative Commons Attribution license (http://creativecommons.org/licenses/by/4.0/). 